\title{
DESIGN PARAMETERS FOR FUEL BATTERIES OPERATING IN A ZERO $G$ FIELD
}

\author{
A. P. Hardt, H. M. Cota, J. L. Fick and T. Katan \\ Materials Sciences Laboratory, Lockheed Missiles and Space Company, \\ Palo Alto, California, U.S.A.
}

\begin{abstract}
Some design parameters of a hydrazine-oxygen fuel battery operating in a zero $G$ field are described in a digital computer programming treatment. The power balance for a battery employing a gas-producing electrode and an electrolyte pump is treated; optimum power densities and flow rates are established.
\end{abstract}

\section{INTRODUCTION}

WiTHIN the last decade fuel cell technology has advanced from the research stage to the development of hardware prototypes. Periods of alternating optimism followed by disillusionment have given way to the conviction that existing problems are amenable to solution by the same approach that has proven so successful in other engineering applications. Fuel cells, being electrochemical devices, suffer polarization; being chemical plants, they have waste products which nust be removed; and being energy converters, they have heat-exchange problems. Each problem by itself is not unduly difficult but in combination with requirements of minimum bulk or mass coupled with maximum lifetime and reliability, they tax the ingenuity of the designer.

Experience has shown that generally there exists quite a degree of latitude in the choice of design parameters, and the mutual dependence of the variables is not immediately obvious. In a recent computer analysis ${ }^{1}$ on the performance of a fuel cell operating with gas-fed electrodes, the electrochemistry of fuel cell technology was reviewed, and the conclusion was reached that the net power level reached an optimum value chiefly determined by current density, being only slightly affected by electrolyte flow rate. Actual fuel cells employ porous electrodes which are quite insensitive to current density in the range of their operation. Furthermore, some systems tend to build up inhibiting phases which, by changing the effective conductance of the electrolyte, affect the cell voltage significantly, and the flow rate is then important. Such systems have been studied by us and this is a report on the digital computer analysis of our findings. 
This study is based on the hydrazine-oxygen system,

$$
\begin{gathered}
\mathrm{N}_{2} \mathrm{H}_{4}(\mathrm{aq})+4 \mathrm{OH}^{-} \rightarrow \mathrm{N}_{2}(\mathrm{~g})+4 \mathrm{H}_{2} \mathrm{O}+4 \mathrm{e}^{-} \\
\mathrm{O}_{2}(\mathrm{~g})+2 \mathrm{H}_{2} \mathrm{O} \rightarrow 4 \mathrm{OH}^{-}-4 \mathrm{e}^{-} .
\end{gathered}
$$

The anode liberates gaseous nitrogen, equation (1), which tends to be removed spontaneously in a gravitational field giving rise to a convection current which in turn can be utilized for circulating the electrolyte. In the absence of gravity, the gas tends to accumulate in and around the electrodes, giving rise to a rapid drop in power output. Hence, convection must be supplied by external power which is also necessary to effect the separation of the two phases by a suitable device.

The battery operates as follows. The anolyte is forced by a pump through a porous nickel electrode where it is oxidized. The two-phase spent electrolyte, diluted by the cathodically formed water, is separated in a gas-liquid separator and partially dehydrated in an evaporator. The electrolyte is then stored in a tank where it may be cooled further and replenjshed with fuel.

Here the electrolyte flow rate and the power density are the independent variables if the desired power output of the cell is fixed. As the pumping power must be furnished by the unit itself, some optimum power density must exist which is determined by the flow rate and the current density. The choice of these parameters in an actual design will be further defined by the requirements of fuel efficiency and by the mission duration. This design study is restricted to optimization with respect to minimum cell volune alone.

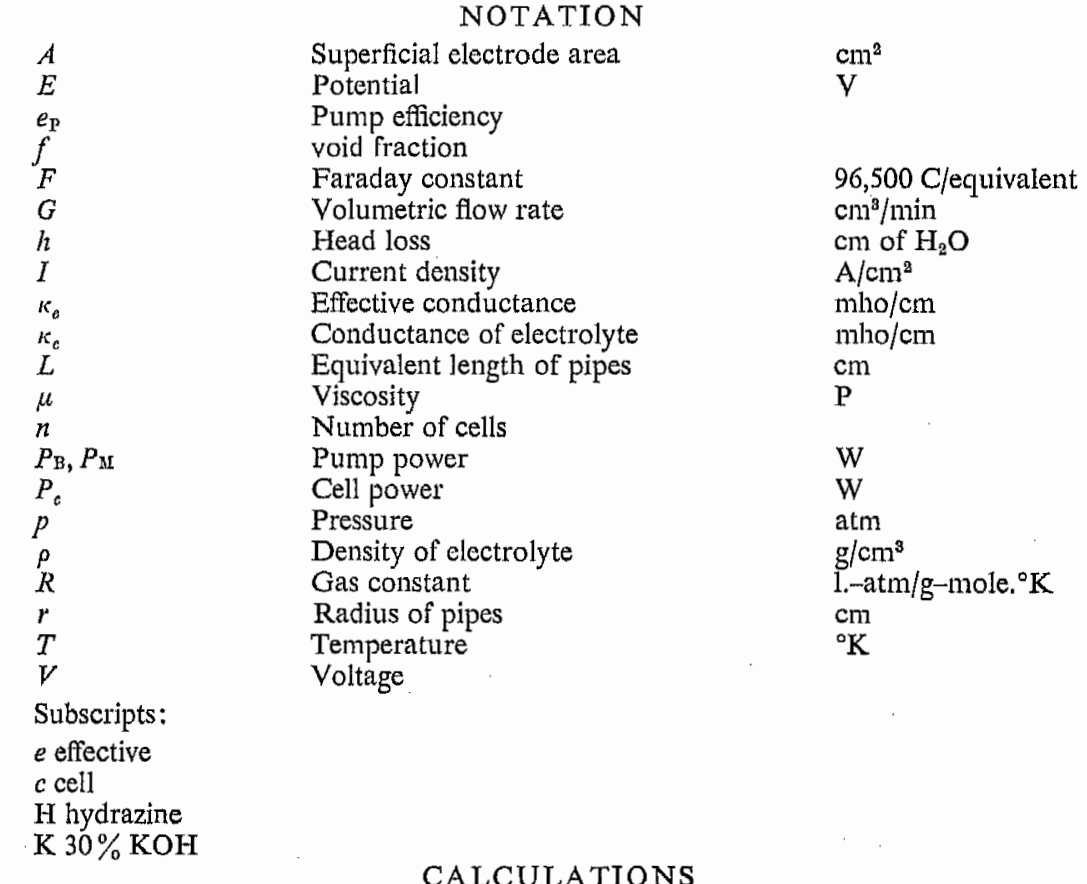

The power output of each cell is given by

$$
P_{o}=I\left(V_{c}^{\circ}-\Sigma \Delta E_{\text {chem }}-\Sigma \Delta E_{\text {conc }}-I \frac{\mathrm{A}}{\kappa}\right)
$$


The open-circuit potential of the hydrazine-oxygen fuel cell operating continuously with $0.2 \mathrm{M}$ hydrazine in 30 per cent $\mathrm{KOH}$ electrolyte at $40^{\circ} \mathrm{C}$ is approximately $0.75 \mathrm{~V}$. The apparent activation polarization is computed by the Tafel equation

$$
\Delta E_{\text {chem }}=a+b \log I
$$

using the constants given in Table 1 . For the purpose of this study the constants $a$ and $b$ must be thought of as being empirical constants only.

TABLE 1. EXPERIMENTALly DETERMINEd CONSTANTS

\begin{tabular}{ccccc}
\hline Electrode & $a$ & $b$ & $c$ & \multicolumn{1}{c}{$\begin{array}{c}\mathrm{L} \\
\mathrm{V}\end{array}$} \\
\hline $\begin{array}{c}\text { Porous nickel anode, } \\
\text { black platinum plated }\end{array}$ & 0.010 & $\mathrm{~V}$ & $\mathrm{~V}$ & $\mathrm{~A} / \mathrm{cm}^{2}$ \\
\hline \begin{tabular}{c} 
Carbon cathode \\
\hline
\end{tabular} & $2.5 \times 10^{-5}$ & 0.0038 & 0.40 & 0.295 \\
\hline
\end{tabular}

The apparent concentration polarization is computed by

$$
\Delta E_{\mathrm{conc}}=c \log \left[I_{L} /\left(I_{L}-I\right)\right]
$$

where the values of the limiting current, $I_{L}$, are considered constant. This assumption is a reasonable one for porous electrodes which exhibit a substantially higher limiting current than solid electrodes, even though the limiting current is not very pronounced or reproducible due to the great variation of reaction rates within the pores. At the present stage of porous electrode technology the use of experimental performance characteristics is the most meaningful.

The last term in equation (3) represents the voltage drop across the electrolyte, here expressed in terms of effective conductance which is affected by the void fraction, or volume fraction, occupied by the non-conducting phase, ${ }^{2}$

$$
\kappa_{B}=\kappa_{c}(1-f)^{3} /^{2} \text {. }
$$

The void fraction, $f$, is determined by the current and the electrolyte flow,

$$
f=I A R T /(4 p F G+I A R T) .
$$

Fig. 1 shows the values of the effective conductance as a function of flow rate, with current density as a parameter. This treatment assumes the limiting case of generation of the void fraction at the entrance of the electrolyte. Fig. 2 shows the effect of the void fraction on cell voltage as a function of current density at varying flow rates. Evidently the cells polarize rapidly at the low flow rates. The same data are plotted in Fig. 3 showing that the cell voltage attains a plateau after the flow rate exceeds $200 \mathrm{~cm}^{3} / \mathrm{min}$.

By equation (3) these data can be utilized in the calculation of the power density. .Fig. 4 shows the cell power as a function of flow rate where the rapid attainment of a plateau is again evident. Equally significant is the appearance of a maximum power density at approximately $0.16 \mathrm{~A} / \mathrm{cm}^{2}$. Replotting these data on Fig. 5 results in the attainment of a series of maxima with insignificant gain in power density at higher flow rates. Laboratory tests with aged electrodes and well circulated electrolyte reproduce these data within experimental limits of accuracy. ${ }^{3}$ 


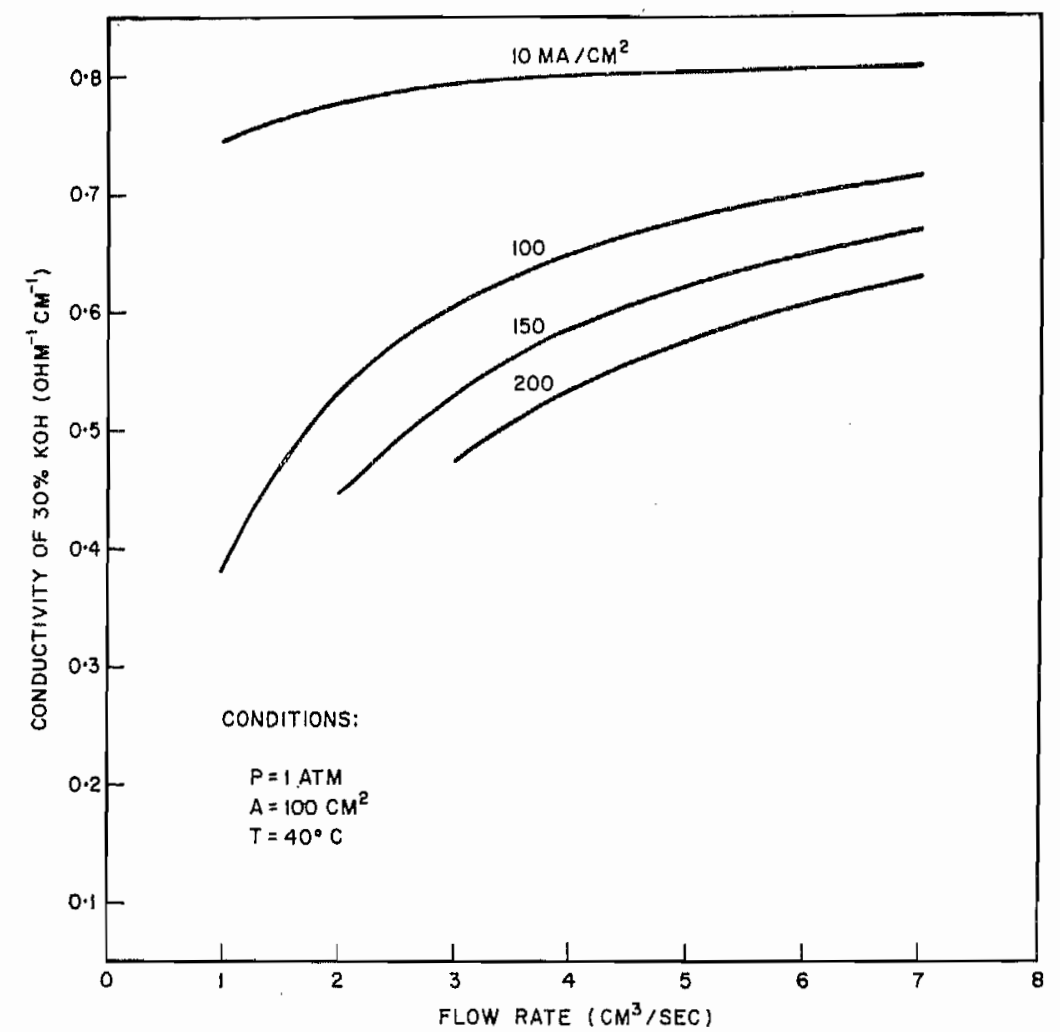

FIG. 1. Effective specific conductance.

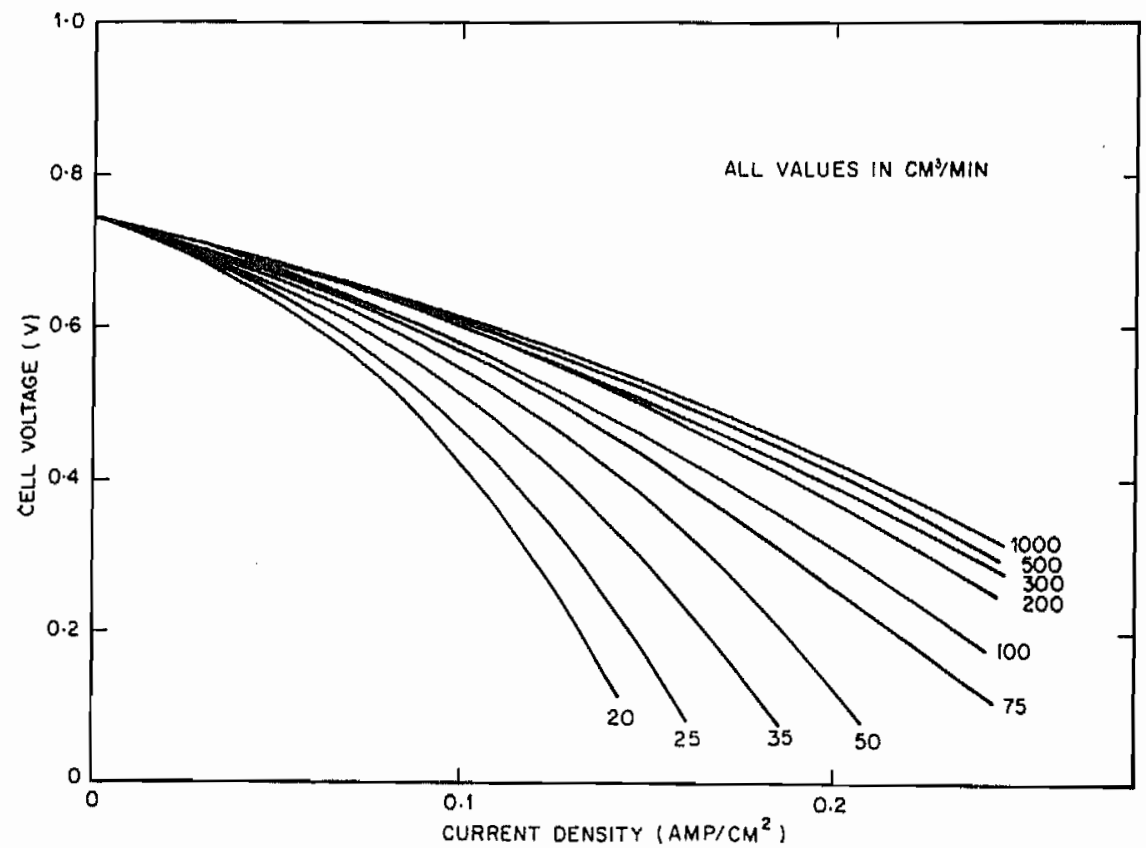

FIG. 2. Effect of volume flow rate on cell voltage. 


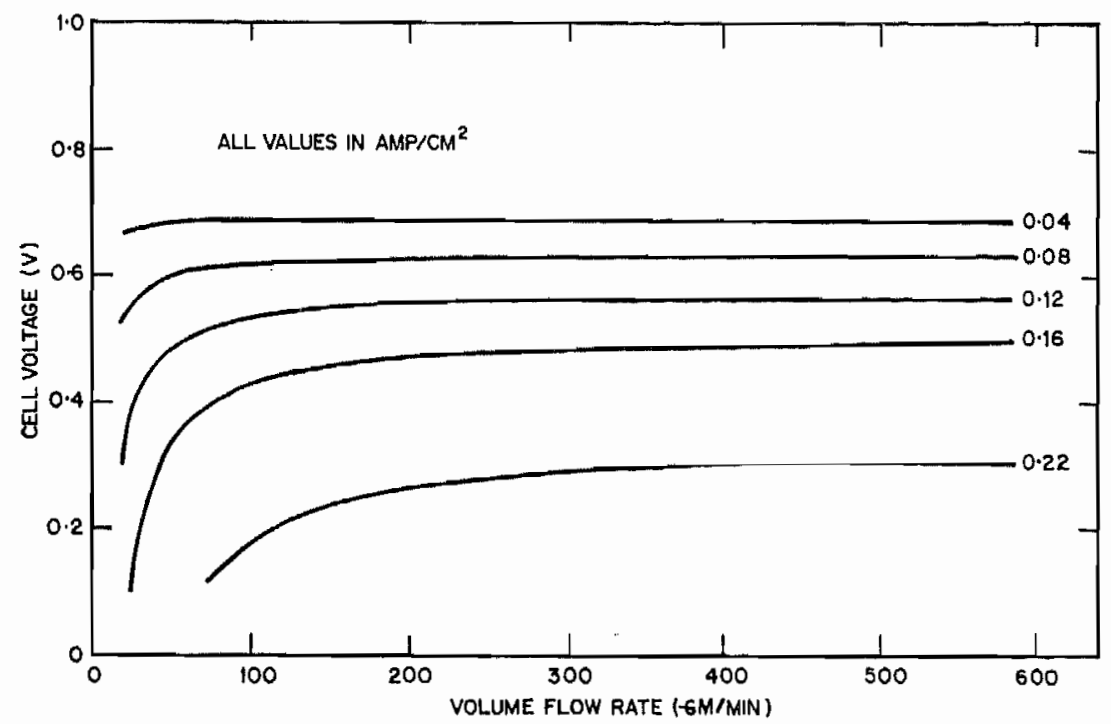

FIG. 3. Effect of current density on cell voltage.

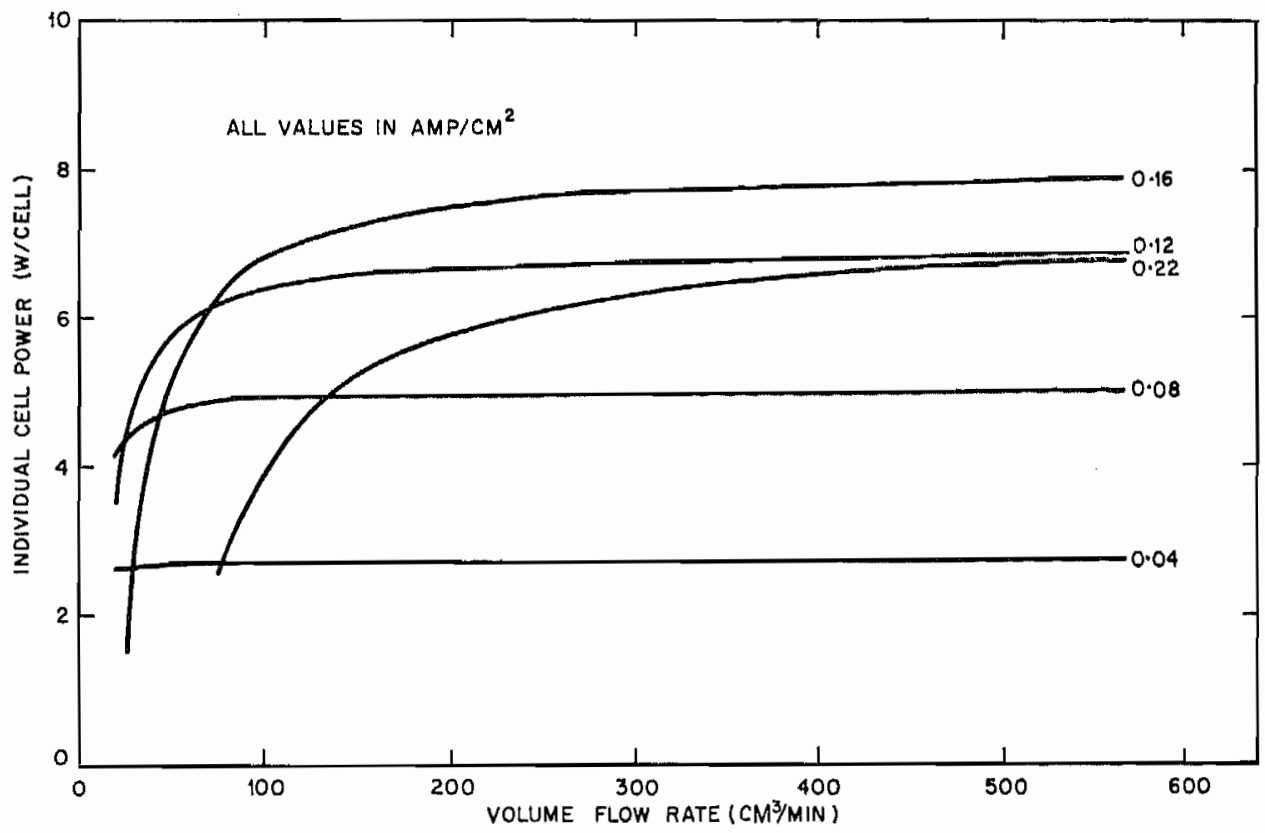

FIG. 4. Effect of current density on cell power. 


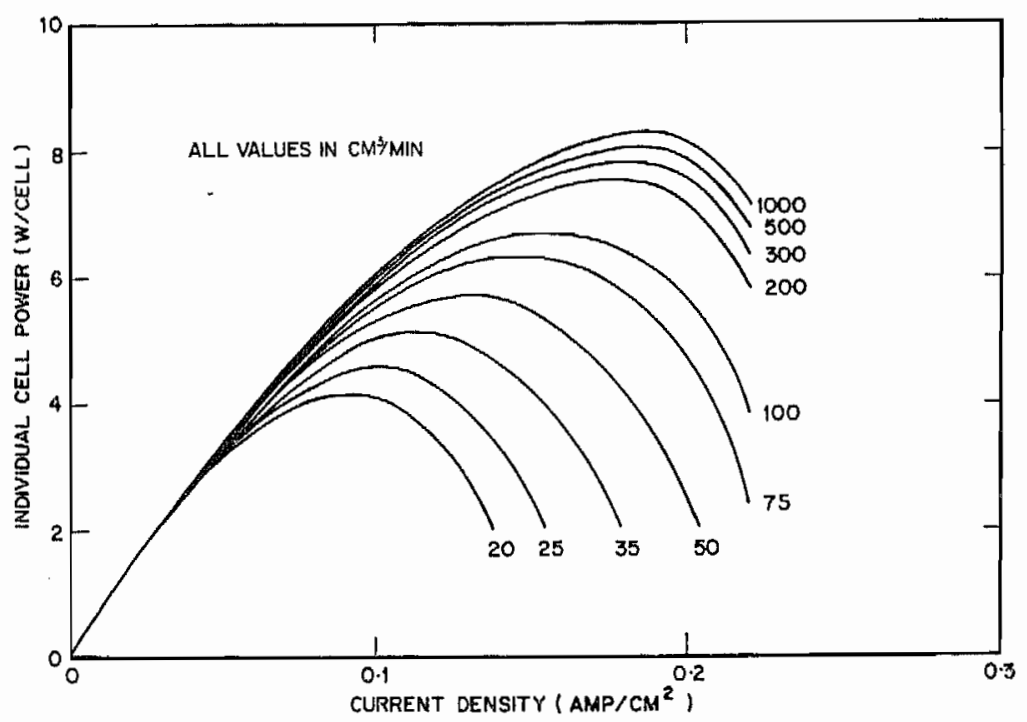

FIG. 5. Effect of volume flow on cell power.

The net power output is determined by the pumping power which is best related to the various hydraulic head losses in the system. ${ }^{1}$ For illustrative purposes this design problem is solved for ten cells placed in series with parallel electrolyte flow. The main head loss is experienced in the lines connecting the cell with the auxiliary units. This is the only part of the system in which turbulence plays an important part as the flow in all other components is laminar. The Reynolds Number is

$$
N_{\mathrm{Re}}=\left(\frac{4 \rho_{\mathrm{K}} n}{60 \pi(2 r) \mu}\right)_{G}
$$

such that

$$
\begin{gathered}
\Delta h_{\mathrm{Line}}=\frac{8 \mu L n}{\rho_{\mathrm{H}} 60 g \pi r^{4}} G \quad \text { for } N_{\mathrm{Re}} \leq 2100, \\
\Delta h_{\mathrm{Line}}=\frac{0.0035 \rho_{\mathrm{K}} L n^{2} G^{2}}{\rho_{\mathrm{H}}(60)^{2} g \pi^{2} r^{5}}+\frac{0 \cdot 264 \rho_{\mathrm{K}} L n G}{2 \rho_{\mathrm{H}} 60 g \pi r^{4}}\left(\frac{\mu}{\rho_{\mathrm{T}}}\right)^{0 \cdot 42} \text { for } N_{\mathrm{Re}} \geq 2100 .
\end{gathered}
$$

Turbulence is found to occur with pipes of $\frac{1}{4}$-in nominal diameter at a mass flow rate of $100 \mathrm{~cm}^{3} / \mathrm{min}$, above which the pumping power increases logarithmically.

Additional, though smaller, pressure drops occur at the tank exit,

$$
\Delta h_{\mathrm{tank}}=\frac{0.75}{2 g(60)^{2} \pi^{2} r^{4}}\left(\frac{\rho_{\mathrm{IK}}}{\rho_{\mathrm{H}}}\right) n^{2} G^{2}
$$

the separator

$$
\Delta h_{\text {separator }}=19 \cdot 5 \text {, }
$$

and the cell

$$
\Delta h_{\text {cell }}=2 \cdot 72 \times 10^{-2} G .
$$

The last two pressure drops were determined experimentally. 
The total head to be overcome is merely the sum of the values computed above,

$$
P_{B}=1.64 \times 10^{-6} n G \Sigma \Delta h / e_{P}
$$

where the pump efficiency, $e_{P}$, is a function of the flow rate and is characteristic of the pump used. For practical reasons the pumping power is not a continuous function, but at very low flow rates the size of the pump is chosen to be

while for larger loads

$$
P_{M}=n / 10 \mathrm{~W} \text { where } P_{B} \leq n / 10,
$$

$$
P_{M}=n / 10+\left(P_{B}-n / 10\right) / 0.8 \mathrm{~W} \text { where } P_{B}>n / 10 .
$$

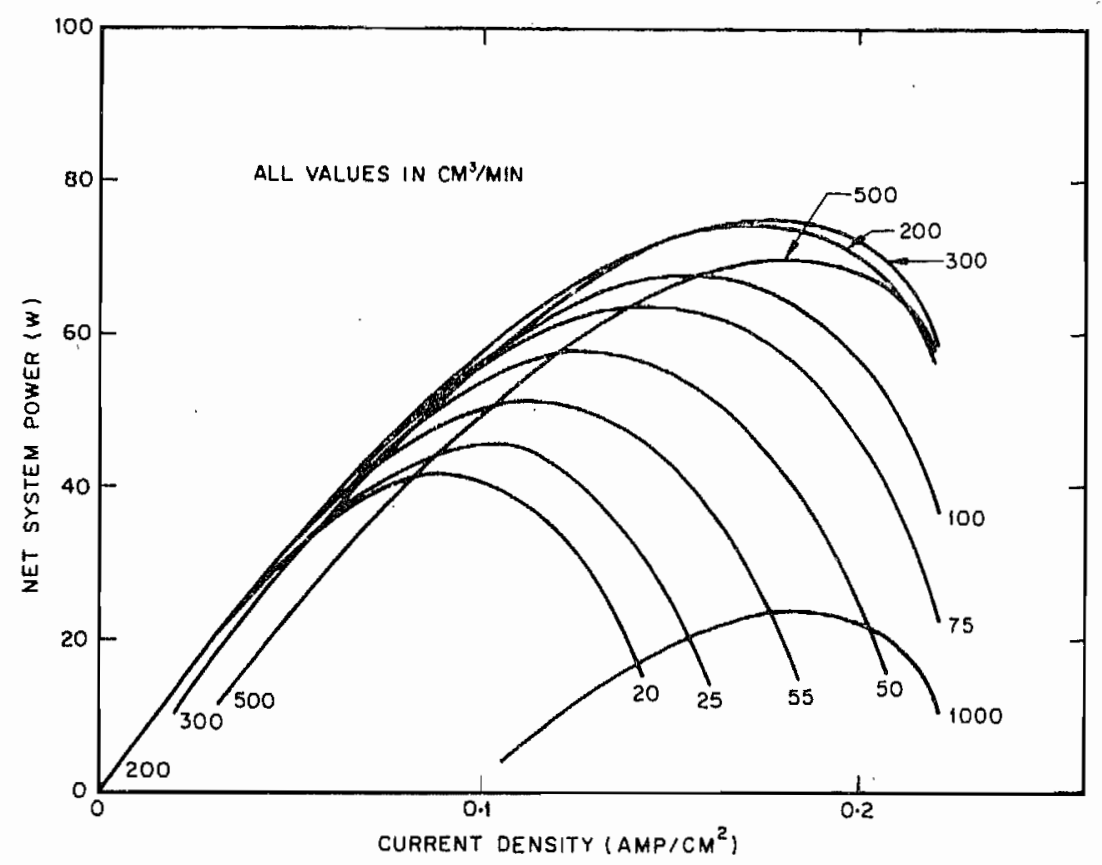

FIG. 6. Effect of volume flow rate on net system power, ten cells.

The net power of the cell is simply the difference between the gross cell output and the pump power,

$$
P=n P_{e}-P_{M}
$$

Figure 6 shows the net battery power as a function of current density. The maximum power is seen to occur at approximately $0.18 \mathrm{~A} / \mathrm{cm}^{2}$ and at a flow rate of $200 \mathrm{~cm}^{3} / \mathrm{min}$. This maximum power is not necessarily the optimum power, as the higher mass of the pump may make a lower power density more desirable.

\section{CONCLUSION}

The feasibility and method of determining the operating characteristics of a ten-cell hydrazine-oxygen fuel battery employing porous electrodes at zero gravity is shown by means of a digital computer. The conclusions apply if the purpose of the design is to minimize the size of the cell. By programming in such a manner that only maxima within certain desirability limits are considered, this technique can 
be utilized in the optimization of the total system with respect to mass, if the mass of the components is known as a function of flow rate or with respect to life expectancy or fuel efficiency if these are known as a function of power density.

Acknowledgements-We wish to acknowledge the financial support of this research by the U.S. Navy, Bureau of Weapons under the research contract NOw 60-0738-d. We thank Mr. R. W. Holsinger for his assistance in the work.

\section{REFERENCES}

1. M. EISENBERG, Electrochim. Acta 6,93 (1962).

2. R. E. DE LA RuE and C. W. TOBIAs, J. Electrochem. Soc. 106, 827 (1959).

3. T. Katan, M. Chin and G. W. Allen, 5th Nat. Symp. Soc. Aerospace Matl. Proc. Engs., Philadelphia, 1963. p. 11, June 2-5, 1963. 